\title{
Influência dos anticoagulantes e da temperatura de armazenamento sobre os niveis sanguíneos de nitrito
}

\section{Effects of anticoagulants and storage temperature on blood nitrite levels}

Etiane Tatsch'; Guilherme Vargas Bochi'; Renata da Silva Pereira'; Helena Kober3; Jarbas Rodrigues de Oliveira ${ }^{4}$; Rafael Noal Moresco ${ }^{5}$

\begin{tabular}{l|l}
\multicolumn{1}{c|}{ Unitermos } & res U mo \\
\hline Óxido nítrico & $\begin{array}{l}\text { A mensuração dos metabólitos do óxido nítrico pode ser útil para a melhor compreensão de diferentes } \\
\text { processos fisiopatológicos. Este estudo avaliou a influência de diferentes anticoagulantes (ácido } \\
\text { etilenodiaminotetracético [EDTA], citrato e heparina) e do armazenamento a }-20^{\circ} \mathrm{C} \text { por quatro meses } \\
\text { sobre os níveis de nitrito, sendo estes mensurados em amostras de soro e plasma pelo método de Griess. } \\
\text { Reagente de Griess }\end{array}$ \\
$\begin{array}{l}\text { Ostabilidade } \\
\text { Onticoagulantes }\end{array}$ & $\begin{array}{l}\text { significativamente os níveis de nitrito, independentemente de as dosagens serem realizadas em amostras } \\
\text { frescas ou naquelas mantidas a }-20^{\circ} \mathrm{C} \text { por quatro meses. }\end{array}$ \\
Armazenamento &
\end{tabular}

The measurement of nitric oxide metabolites may be useful for better understanding of different physiopathological processes. Thus, the aim of this study was to evaluate the influence of different anticoagulants (EDTA, citrate and heparin) and four-month storage at $-20^{\circ} \mathrm{C}$ on nitrite levels. The serum and plasma samples were analyzed by using the Griess method. The type of sample (serum or plasma) or anticoagulant used in the collection did not influence on nitrite levels significantly, regardless the fact they were fresh or four-month samples stored at $-20^{\circ} \mathrm{C}$.

key words

Nitric oxide

Nitrite

Griess reagent

Stability

Anticoagulants

Storage

1. Aluna de mestrado do Programa de Pós-Graduação em Ciências Farmacêuticas do Centro de Ciências da Saúde da Universidade Federal de Santa Maria (UFSM).

2. Aluno de Mestrado do Programa de Pós-Graduação em Farmacologia, Centro de Ciências da Saúde da UFSM.

3. Pesquisadora do Laboratório de Bioquímica Clínica do Departamento de Análises Clínicas e Toxicológicas do Centro de Ciências da Saúde da UFSM.

4. Professor titular da Pontifícia Universidade Católica do Rio Crande do Sul (PUCRS); coordenador do Laboratório de Biofísica Celular e Inflamação da PUCRS.

5. Professor adjunto do Departamento de Análises Clínicas e Toxicológicas do Centro de Ciências da Saúde da UFSM. 


\section{Introdução}

O óxido nítrico (NO) possui funções metabólicas altamente ativas, principalmente na regulação das atividades cardiovasculares. O NO formado nas células endoteliais promove vasodilatação, aumento do fluxo sanguíneo, inibição da agregação e da adesão plaquetária, redução da migração e adesão leucocitária e diminuição da proliferação de células musculares lisas ${ }^{(2)}$. Assim, todas essas funções desempenhadas pelo NO contribuem para a prevenção da aterosclerose ${ }^{(7)}$. Alguns fatores de risco para aterosclerose, como a dislipidemia, obesidade, diabetes mellitus e hipertensão arterial, podem estar especificamente associados a anormalidades da vasodilatação endotelial mediada pelo NO, ocasionando vasoconstrição, agregação plaquetária, adesão de neutrófilos para o endotélio, redução da luz dos vasos e, em última instância, isquemia dos tecidos ${ }^{(1)}$.

Embora o NO seja uma molécula importante na manutenção cardiovascular, trata-se de um radical livre, sendo que sua síntese exacerbada está relacionada com vários processos patológicos ${ }^{(5)}$. Sabe-se que, na presença de ânions superóxidos liberados por macrófagos, o NO é metabolizado à peroxinitrito, causando dano celular. Portanto é possível observar que, em situações de estresse oxidativo, o efeito benéfico do NO é suprimido, ocorrendo o impedimento de suas ações fisiológicas no endotélio vascular. Assim, no estágio avançado de aterosclerose, percebem-se uma redução dos níveis de $\mathrm{NO}$ e um aumento de sua decomposição em peroxinitrito ${ }^{(4)}$.

Devido à importante função desempenhada pelo NO, torna-se relevante a mensuração de seus níveis nos tecidos biológicos a fim de elucidar o seu real envolvimento nas doenças cardiovasculares e, talvez, atuar como um possível marcador para aterosclerose ${ }^{(7)}$. A determinação indireta do NO pode ser realizada por dosagem plasmática ou urinária dos seus metabólitos nitrato e nitrito, sendo que o método frequentemente utilizado na mensuração desses íons baseia-se na reação de Griess(2). Os valores de nitrito obtidos pela reação de Griess podem sofrer influências de acordo com o tipo de anticoagulante utilizado na coleta ${ }^{(9)}$. Desta forma, este trabalho visa avaliar a influência de algumas variáveis pré-analíticas como o tipo de anticoagulante utilizado na colheita e a temperatura de armazenamento da amostra sobre os níveis sanguíneos de nitrito mensurados pelo método de Griess automatizado.

\section{Métodos}

Para a análise dos níveis de nitrito, foram coletadas amostras de sangue pela técnica padrão de punção venosa de 10 indivíduos saudáveis adultos e de ambos os sexos. Essas amostras foram transferidas para tubos a vácuo (Vacutainer ${ }^{\circledast}$, BD Diagnostics, EUA) sem anticoagulante e para tubos contendo os anticoagulantes heparina, ácido etilenodiaminotetracético (EDTA) e citrato de sódio a $3,2 \%$. As amostras coletadas foram rotineiramente centrifugadas a $2.800 \mathrm{rpm}$ por 15 minutos para a separação das amostras de soro e plasma. A quantificação dos níveis de nitrito foi realizada nas amostras dentro de, no máximo, 2 horas após a colheita, sendo as dosagens realizadas em triplicata. Depois, as amostras foram armazenadas à temperatura de $-20^{\circ} \mathrm{C}$ por quatro meses, sendo que, ao término desse período, foram realizadas novamente as dosagens de nitrito. Os sujeitos com diabetes mellitus, histórico de doenças cardíacas, acidente vascular cerebral (AVC) ou com processos inflamatórios agudos ou crônicos foram excluídos do estudo. Este protocolo de pesquisa foi aprovado pelo Comitê de Ética em Pesquisa da Universidade Federal de Santa Maria (Processo $\mathrm{n}^{\circ}$ 0198.0.243.000-09) e todos os participantes assinaram o termo de consentimento livre e esclarecido.

Os níveis de nitrito foram mensurados nas amostras de soro e plasma pelo método de Griess adaptado ao sistema automatizado Cobas Mira ${ }^{\circledR}$ (Roche Diagnostics) previamente padronizado e validado em nosso laboratório $^{(8)}$. Nesta técnica, $30 \mu \mathrm{l}$ de amostra são pipetados para a cubeta de reação, sendo posteriormente adicionados 150 $\mu \mathrm{l}$ do reagente de Griess [sulfanilamida a 2\%, N-(1-naftil) etilenodiamina a 0,2\% e ácido ortofosfórico em água destilada/deionizada]. A mistura amostra/reagente de Griess é incubada por 300 segundos e a leitura, realizada em $550 \mathrm{~nm}$. Todas as incubações são realizadas a $37^{\circ} \mathrm{C}$ e os resultados são expressos em $\mu \mathrm{mol} / \mathrm{l}$. Esta técnica apresenta coeficiente de variação (CV) intraensaio de $6,3 \%$ e interensaio de $5,7 \%$, além de limite de detecção de $2,5 \mu \mathrm{mol} / \mathrm{l}$ e linearidade até $80 \mu \mathrm{mol} / \mathrm{l}$.

Os resultados estão expressos em média \pm desvio padrão, sendo analisados estatisticamente pela análise de variância (ANOVA) com pós-teste de Tukey, além do teste $t$ de Student para amostras pareadas, sendo $p<0,05$ considerado estatisticamente significativo. 


\section{Resultados}

Os indivíduos avaliados nesse estudo tinham idade de $29,8 \pm 5,1$ anos. Os níveis de nitrito obtidos nas amostras recém-colhidas (frescas) foram: 12,61 $\pm 3,97 \mu \mathrm{mol} / \mathrm{l}$ (soro), $11,64 \pm 3,68 \mu \mathrm{mol} / /$ (plasma-EDTA), 10,2 $\pm 3,57 \mu \mathrm{mol} / \mathrm{l}$ (plasma-citrato) e 12,25 $\pm 5,2 \mu \mathrm{mol} / /$ (plasma-heparina), sendo que essas diferenças não foram estatisticamente significativas, conforme apresentado na Figura. Os níveis de nitrito obtidos nas amostras mantidas armazenadas a $-20^{\circ} \mathrm{C}$ por quatro meses foram: 14,03 $\pm 6,36 \mu \mathrm{mol} / \mathrm{l}$ (soro), 12,21 \pm $6,43 \mu \mathrm{mol} / \mathrm{l}$ (plasma-EDTA), 11,18 $\pm 7,1 \mu \mathrm{mol} / \mathrm{l}$ (plasmacitrato) e 10,7 $\pm 5,18 \mu \mathrm{mol} / \mathrm{l}$ (plasma-heparina), mas essas diferenças não foram estatisticamente significativas. Além disso, quando realizadas comparações pareadas para cada tipo de amostra (soro ou plasma) nas duas condições testadas (frescas e mantidas a $-20^{\circ} \mathrm{C}$ durante quatro meses), não houve diferença estatisticamente significativa, o que indica que $o$ analito manteve-se estável e que pode ser mensurado em amostras armazenadas durante quatro meses a $-20^{\circ} \mathrm{C}$, independentemente do tipo de amostra utilizada.

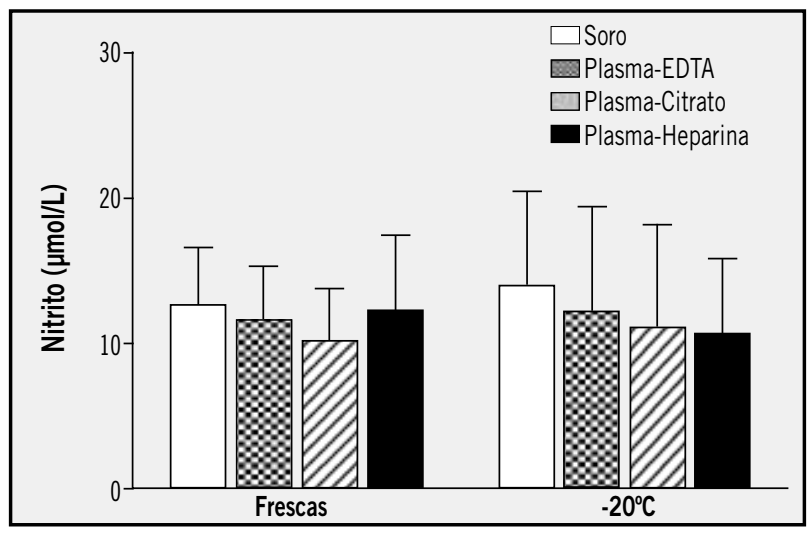

Figura - Níveis de nitrito obtidos nas amostras de soro e plasma recém-colhidas (frescas) e nas amostras mantidas a $-20^{\circ} \mathrm{C}$ pelo período de quatro meses

\section{Discussão}

O presente estudo baseou-se na determinação indireta do NO pela quantificação dos íons nitrito pelo método de Griess, sendo avaliadas algumas variáveis pré-analíticas, uma vez que este marcador apresenta importante papel na fisiologia de diversas patologias(2), principalmente na regulação das atividades cardiovasculares ${ }^{(7)}$. Neste estudo não foram observadas diferenças estatisticamente significativas nos níveis de nitrito, independentemente do tipo de amostra utilizada (soro e plasma frescos) e do tipo de anticoagulante utilizado (EDTA, citrato e heparina), nem nas amostras mantidas a $-20^{\circ} \mathrm{C}$ pelo período de quatro meses, o que indica que os níveis de nitrito mantiveram-se estáveis. Dessa forma, o nitrito também pode ser mensurado em amostras armazenadas durante quatro meses a $-20^{\circ} \mathrm{C}$, independente do tipo de amostra utilizada.

Quanto ao tipo de anticoagulante usado na coleta, foi demonstrado que nenhum deles interferiu significativamente nos níveis de nitrito em amostras recém-colhidas nem naquelas mantidas a $-20^{\circ} \mathrm{C}$ pelo período avaliado neste estudo. Alguns estudos sugerem que o EDTA é o melhor anticoagulante em comparação com a heparina e o citrato para a quantificação dos metabólitos do óxido nítrico, sendo o mais usado em rotinas clínicas e experimentais ${ }^{(9)}$. No entanto, neste estudo conduzido por Ricart-Jané et al., foram determinados simultaneamente os níveis de nitrato e nitrito (NOx) em amostras de plasma, não sendo avaliados os níveis de NOx em amostras de soro ${ }^{(9)}$. Outros estudos demonstraram que o plasma heparinizado pode formar um precipitado sobre a adição do reagente de Griess, tornando este anticoagulante desfavorável para a análise(3). Os metabólitos do óxido nítrico são estáveis a $-20^{\circ} \mathrm{C}$ por um período de um ano no plasma ${ }^{(6)}$. No entanto, nenhum estudo de estabilidade foi realizado em amostras de soro. Segundo nosso conhecimento, este é o primeiro estudo que apresenta uma avaliação preliminar de estabilidade para os níveis de nitrito em amostras de soro.

Com base nos resultados obtidos é possível concluir que os tipos de amostra utilizados (soro ou plasma) e de anticoagulante usado na coleta (EDTA, citrato ou heparina) não influenciaram significativamente os níveis de nitrito, independentemente de esta dosagem ser realizada em amostras frescas ou mantidas a $-20^{\circ} \mathrm{C}$ pelo período de quatro meses. De qualquer forma, faz-se necessária a realização de estudos adicionais que avaliem um número maior de amostras, bem como outras condições de armazenamento com diferentes temperaturas e períodos.

\section{Referências}

1. ARKIN, J. M. et al. Relation of cumulative weight burden to vascular endothelial dysfunction in obesity. Am J Cardiol, v. 101, n. 1, p. 98-101, 2008.
2. ASL, A. Z.; GHASEMI, A.; AZIZI, F. Serum nitric oxide metabolites in subjects with metabolic syndrome. Clin Biochem, v. 41, n. 16-7, p. 1342-47, 2008. 
3. BRYAN, N. S.; GRISHAM, M. B. Methods to detect nitric oxide and its metabolites in biological samples. Free Radic Biol Med, v. 43, n. 5, p. 645-57, 2007.

4. HSICH, E. etal. Vascular effects following homozygous disruption of p47(phox): an essential component of NADPH oxidase. Circulation, v. 101, n. 11, p. 1234-6, 2000.

5. KANEKI, M. et al. Nitrosative stress and pathogenesis of insulin resistance. Antioxid Redox Signal, v. 9, n. 3 p. 319-29, 2007.

6. MOSHAGE, $\mathrm{H}$. et al. Nitrite and nitrate determinations in plasma: a critical evaluation. Clin Chem, v. 41, n. 6, p. 892-6, 1995.
7. NAPOLI, C. et al. Nitric oxide and atherosclerosis: an update. Nitric Oxide, v. 15, n. 4, p. 265-79, 2006.

8. PEREIRA, R. S. et al. A simple, fast and inexpensive automated technique for measurement of plasma nitrite. Clin Chem Lab Med, v. 48, n. 12, p. 1837-9, 2010.

9. RICART-JANÉ, D.; LLOBERA, M.; LÓPEZ-TEJERO, M. D. Anticoagulants and other preanalytical factors interfere in plasma nitrate/nitrite quantification by the Griess method. Nitric Oxide, v. 6, n. 2, p. 178-85, 2002. 